\title{
Canal flare index evaluation for different dog breeds
}

\author{
Paula Regina Silva Gomide ${ }^{*}$ (iD Luís Renato Veríssimo de Souza ${ }^{2}$ iD Caroline Ribeiro de Andrade AD $^{1}$ \\ Rafael Manzini Dreibi ${ }^{\text {iD }}$ Bianca Paola Santarosa ${ }^{3}$ iD Bruno Watanabe Minto ${ }^{1}$ iD
}

${ }^{1}$ Departamento de Clínica e Cirurgia Veterinária, Faculdade de Ciências Agrárias e Veterinárias (FCAV), Universidade Estadual Paulista (UNESP), 14884-900, Jaboticabal, SP, Brasil. E-mail: pagomide@terra.com.br. "Corresponding author.

${ }^{2}$ H. Diagnose Serviços Veterinários, Rio de Janeiro, RJ, Brasil.

${ }^{3}$ Instituto de Ciências Agrárias (ICA), Universidade Federal dos Vales do Jequitinhonha e Mucuri (UFVJM), Unaí, MG, Brasil.

ABSTRACT: This study determined the canal flare index (CFI) of four dog breeds using two distinct femoral regions as a reference. Thirtyfive radiographs of the hip joints of Golden Retrievers (GRG), German Shepherds (GSG), Labrador Retrievers (LRG), and Rottweilers (RG) of both sexes were used. Seventy experimental units were submitted to CFI calculation. Objective (CFIob) and subjective (CFIsub) values of the CFI of each experimental unit were determined according to the anatomical reference used for the calculation. A significant difference in the CFIob between the Golden Retriever and German Shepherd breeds (1.68 \pm 0.16 and 1.49 \pm 0.08 ), and in the CFIsub between Golden Retriever, German Shepherd, and Rottweiler breeds $(2.09 \pm 0.31,1.86 \pm 0.11$, and $1.84 \pm 0.18)$ was reported. The subjective form of measurement showed higher values than the objective form (GRG: $2.09 \pm 0.31 ; G S G: 1.86 \pm 0.11 ; L R G: 2.07 \pm 0.12 ; R G: 1.84 \pm 0.18)$. The CFI values of each breed were similar, suggesting a certain racial pattern. A significant difference in the interobserver assessment for both CFIsub and CFIob, in all races was observed. The CFI analysis identified morphological patterns of the proximal femur in the different races. Results indicated the need for standardization of the anatomical references used to calculate the CFI because there were statistical differences among the measurements among the observers.

Key words: femur, hip dysplasia, prothesis, reproducibility, total hip arthroplasty.

Avaliação do canal flare index femoral de diferentes raças de cães

RESUMO: Objetivou-se determinar o canal flare index (CFI) de quatro raças especificas de cães, utilizando-se duas regiões femorais distintas como referência. Foram analisadas 35 radiografias de articulações coxofemorais de cães das raças Golden Retriever (GGR), Pastor Alemão (GPA), Labrador Retriever (GLR) e Rottweiler (GR), de ambos os sexos, configurando 70 unidades experimentais submetidas ao cálculo do CFI. Determinaram-se os valores objetivo (CFIob) e subjetivo (CFIsub) do CFI de cada unidade experimental de acordo com a referência anatômica utilizada para o cálculo. Houve diferença significativa do CFIob entre as raças Golden Retriever e Pastor Alemão (1,68 $\pm 0,16$

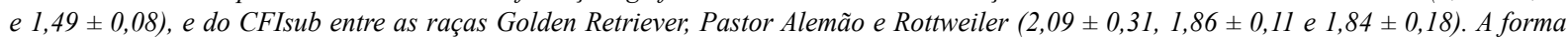
subjetiva de mensuração apresentou valores maiores que a forma objetiva (GGR: 2,09 $\pm 0,31 ; G P A: 1,86 \pm 0,11 ; G L R: 2,07 \pm 0,12 ; G R: 1,84$ \pm 0,18). Os valores de CFI de cada raça se apresentaram similares, sugerindo haver determinado padrão racial. Houve diferença significativa na avaliação interobservadores, tanto do CFIsub quanto CFIob, em todas as raças. A análise do CFI identificou padrões morfológicos do fêmur proximal nas diferentes raças. Os resultados indicaram a necessidade de padronização dos referenciais anatômicos utilizados para o cálculo do CFI, uma vez que houve relevância estatística entre as diferentes mensurações entre os observadores.

Palavras-chave: artroplastia total do quadril, displasia coxofemoral, fêmur, prótese, reprodutibilidade.

\section{INTRODUCTION}

Degenerative hip dysfunctions are prevalent and relevant orthopedic conditions in dogs because they are potentially debilitating and difficult to manage. Represented in large part by the hip dysplasia syndrome, characterized by a progressive degenerative joint disease, which significantly reduces the quality of life of patients (ROBERTS \& McGREEVY, 2010; BERGH \& BUDSBERG, 2014).
The replacement of the diseased joint with prosthetic components, known as total hip arthroplasty (THA), is an effective treatment option, capable of preserving the total functionality of the limb providing pain-free joint movement (BERGH \& BUDSBERG, 2014; KIDD et al., 2016). However, it is not free of complications, of which the most prominent are dislocations, sinking of the femoral stem, femoral fractures, and infection (GANZ et al., 2010). 
More accurate knowledge of the morphology of the proximal femur, as well as the performance of anatomical and morphological studies of this region, could greatly help reduce the alarmingly high complication rates (SEVILKILIMCI \& KARA, 2017). However, canine femoral morphology varies with age and race similar to that of the human femur (CROOIJMANS et al., 2009; BAHARUDDIN et al., 2014).

For the evaluation of femoral morphology during the pre-surgical planning process, one of the tools used is the canal flare index (CFI), which can be translated as the femoral canal enlargement index, which helps in the selection of the femoral stem in planning for THA in both human and veterinary medicine (SEVIL-KILIMCI \& KARA, 2017; SEVILKILIMCI \& KARA, 2020).

In veterinary medicine, there are insufficient data to assess the variation in the geometry of the medullary canal of the proximal femur in dogs. In this sense; although, there have been some studies, there is no consistency regarding the reference values of CFI in femurs of specific dog breeds (SEVIL-KILIMCI \& KARA, 2017), which encourages morphological studies regarding these values. RASHMIR-RAVEN et al. (1992) and DEYOUNG \& SCHILLER (1992) highlighted that the breed of dog can be an important and determinant factor in canine femoral morphology according to their clinical experience. Therefore, this research determined the CFI of four specific breeds of dogs (Rottweiler, German Shepherd, Golden Retriever, and Labrador Retriever) using two distinct femoral regions as a reference.

\section{MATERIALS AND METHODS}

Thirty-five radiographs of the hip joints of both sexes of Rottweilers (Rottweiler Group - GR), German Shepherds (the German Shepherd Group - GGS), Golden Retrievers a (Golden Retriever Group - GGR), and Labrador Retrievers (a Labrador Retriever Group - GLR) were used to configure 70 experimental units (right and left femurs). These values were used to calculate the CFI, with GR and GGS composed of 20 femurs each, GGR composed of 14 femurs, and GLR of 16 femurs.

Radiographic examinations of hips of skeletally mature dogs selected for assessing hip dysplasia were selected following the positioning patterns of the Orthopedic Foundation for Animals (OFA): extended ventrodorsal projection of the hip, with the hind limbs extended and parallel to each other with pelvic symmetry having knees, patellae, and iliac wings included in the radiographs. Femurs that presented radiographic signs of bone neoplasia or femoral fractures were excluded from the study. Cassettes $(35 \times 43 \mathrm{~cm})$ were placed inside the bucky and properly collimated such that the entire image of the pelvis and femurs were contained in the radiographs. The Siemens X-ray machine (Siemens Healthcare of Brazil, Rio de Janeiro, RJ, Brazil) was used to obtain the images. To perform the exams, the animals were anesthetized with propofol (Propovan - Cristália, São Paulo, SP, Brazil) intravenously at a dose of $6 \mathrm{mg} / \mathrm{kg}$.

In an attempt to minimize errors, three evaluators calculated the CFI (orthopedic surgeons: 1,2, and 3). Each evaluator made three measurements for each experimental unit using an analog caliper.

In this study, two reported methodologies measured the CFI to assess the discrepancy in the values obtained between them when used in the same experimental unit. Objective CFI (CFIob) was the methodology described by RASHMIR-RAVEN et al. (1992), in which the CFI was calculated from the ratio between the intracortical width at the level of the lesser trochanter and the midpoint of the femoral length. For subjective CFI (CFIsub), the methodology described by GANZ et al. (2010) and PUGLIESE (2014), which is the ratio between the intracortical width at the level of the lesser trochanter and the femoral isthmus was used (Figure 1).

For better standardization of radiographic samples, they were measured on a scale of $50 \%$ of the actual size (the values obtained were doubled to achieve the final result), which was obtained using Microsoft Paint 10.0.18362.1 (Microsoft - Redmons/ Washington, United States) where the measurement was performed on the basis of pixels. Each grid line of the software corresponded to 10 pixels, which in turn corresponded to $0.25 \mathrm{~cm}$. In a $100 \%$ zoom image, each line of the ruler provided by the software comprised two grid lines, that is $0.5 \mathrm{~cm}$ (Figure 2).

The normality tests (Shapiro-Wilk) and graphic analysis (QQ Plot and histogram) assessed the distribution of variables. Descriptive statistics (mean, standard deviation, and 95\% confidence intervals) were generated. An analysis of variance (ANOVA) was used for repeated measures, followed by the Tukey test to verify the evaluations between the different observers and the repetitions of the evaluations between the same evaluators. Statistical differences were considered when $\mathrm{p} \leq 0.05$. The analyses were performed with the aid of the Statistical Analysis Software, SAS (SAS Institute, Cary, North Carolina, United States). 


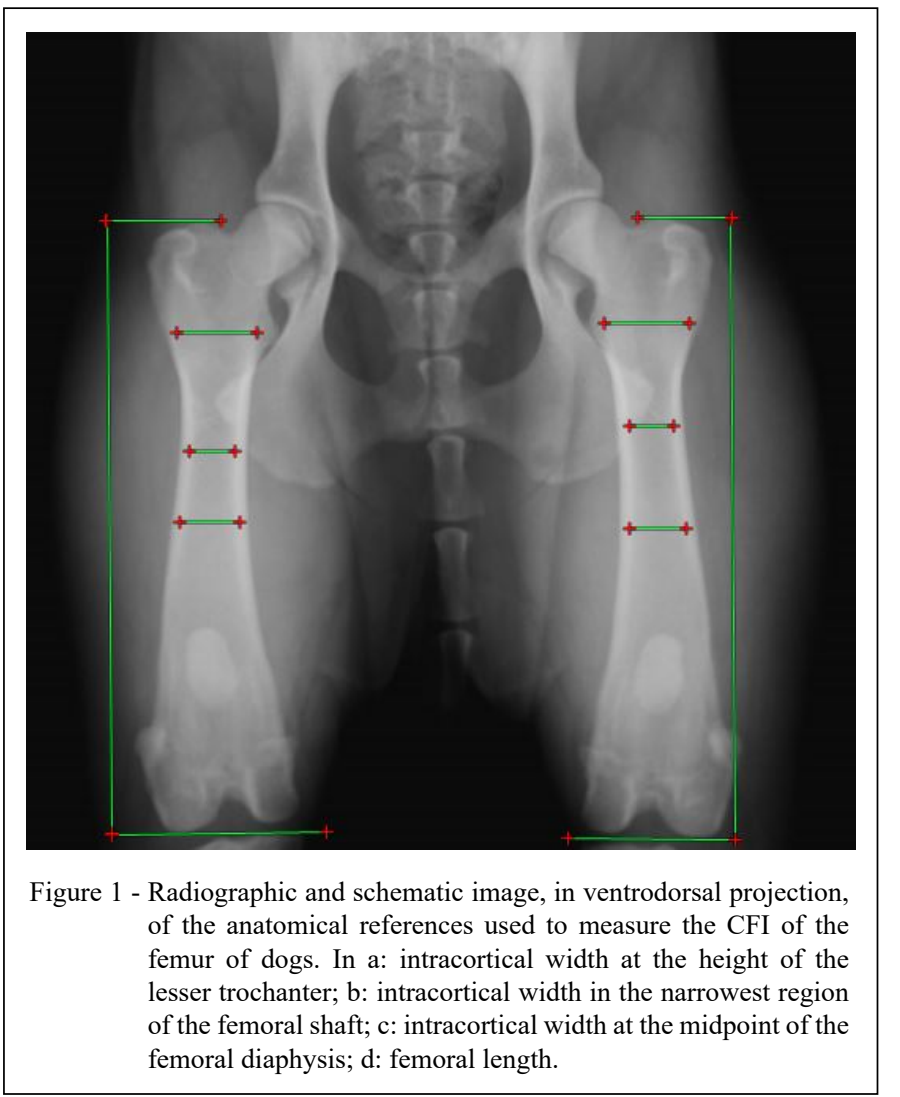

\section{RESULTS AND DISCUSSION}

For measuring CFIob, there was a significant difference between the values of Golden Retriever and German Shepherd, which presented averages of 1.68 and 1.49 , respectively. In the CFIsub assessment, there was a significant difference between the Golden Retriever, German Shepherd, and Rottweiler breeds with means of $2.09,1.86$, and 1.84, respectively (Figure 3 ).

Regarding the methods for measuring CFI (objective and subjective), it was observed that the subjective methodshad significantly higher values than did the objective value and each race fell within a specific standard CFI interval according to the $95 \%$ confidence interval (Table 1). No significant difference in the intraobserver evaluations was observed; however, in the interobserver evaluation, there was a significant difference in both CFIsub and CFIob for the Golden Retriever (GGR), Labrador Retriever (GLR), and Rottweiler (GR) breeds between evaluator 3 and evaluators 1 and 2 . In the German Shepherd breed
(GPA) all evaluators presented statistically different values for CFIob and CFIsub (Table 2).

Several authors have searched for a femoral implant design that can eliminate the complications that involve inserting the femoral component in the cementless fixation system (HENDERSON et al., 2017; SCHMIDUTZ et al., 2017). BOER and SARIALI (2016) developed a study that comparatively evaluated two prosthetic models (linear design nail and anatomical design nail), and the authors concluded that the anatomical design nail exhibited a superior result because it had greater filling in the proximal metaphyseal part of the canal femoral area, providing a lower subsidence rate by preventing micro-movement of this region.

FLECHER et al. (2010) and SARIALI et al. (2012) observed encouraging results in a clinical trial with the use of an anatomical model nail; thus, supporting the hypothesis that knowledge of the proximal anatomy of the canine femur may be essential for choosing the prosthetic model to be used for each patient.

The results of this study, with a $95 \%$ confidence interval, demonstrated the existence of 


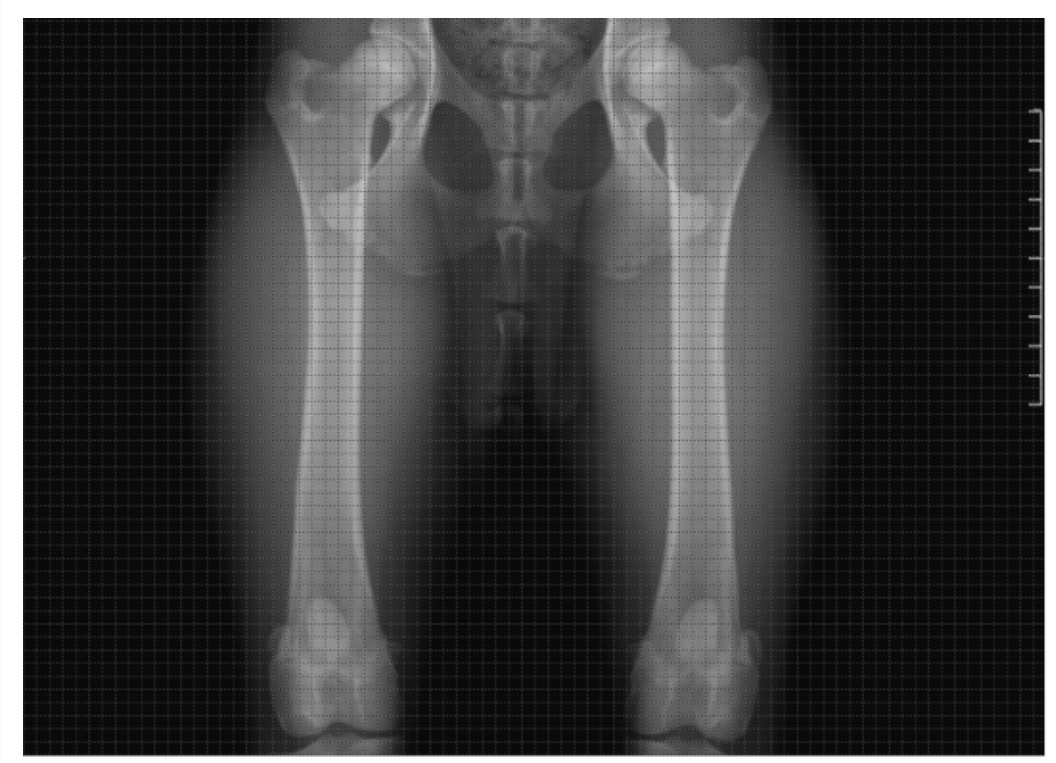

Figure 2 - Radiographic and illustrative image of the standardization performed using Microsoft Paint software. Note the $100 \%$ zoom of the image resulting in an image with $50 \%$ of the actual size (10-line ruler, each one corresponds to 0.5 $\mathrm{cm}$, according to the pixels and grid lines of the software).

specific reference values for each race evaluated, revealing the need for a racial morphological pattern.

Studies that determine the CFI standard value in specific breeds of dogs are not described in the veterinary literature; however, in the human literature, it is possible to find data on morphological patterns of the proximal femur in different ethnicities (GANZ et al., 2010). In this context, RAWAL et al. (2012) studied the variation in the proximal femoral morphology of Indians by comparing them with

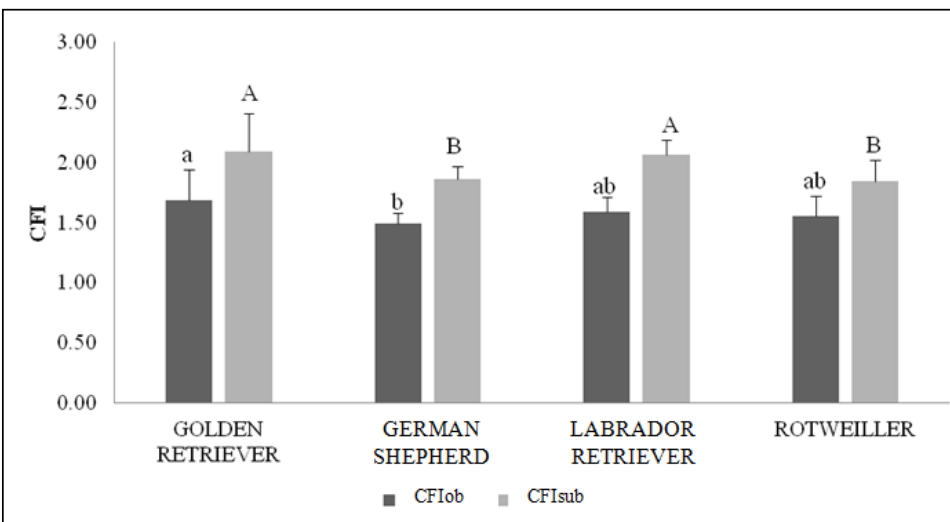

Figure 3 - Mean and standard deviation of CFI measured objectively and subjectively for dogs of different breeds: Golden Retrievers (GRG), German Shepherds (GSG), Labrador Retrievers (LRG), and Rottweilers (RG).

Different lower case letters $(a, b)$ indicate statistical difference $(p \leq 0.05)$ among the breeds for objective measurements.

Different capital letters $(A, B)$ indicate statistical difference $(\mathrm{p} \leq 0.05)$ among the breeds for subjective measurements. 
Table 1 - Mean, standard deviation (SD), 95\% confidence interval (CI) and comparison of CFI objective (CFIob) and subjective (CFIsub) measurements for dogs of different breeds: Golden Retrievers (GRG), German Shepherds (GSG), Labrador Retrievers (LRG), and Rottweilers (RG).

\begin{tabular}{|c|c|c|c|c|c|c|}
\hline \multirow[t]{2}{*}{ Breed } & \multirow[t]{2}{*}{$\mathrm{N}$} & \multicolumn{2}{|c|}{----------------------'CFIob------------------- } & \multicolumn{2}{|c|}{------------------CFIsub------------------- } & \multirow[t]{2}{*}{ P value* } \\
\hline & & Mean (SD) & CI $95 \%$ & Mean (SD) & CI $95 \%$ & \\
\hline GRG & 14 & $1.68(0.16)$ & $1.54-1.83$ & $2.09(0.31)$ & $1.91-2.27$ & $<0.001$ \\
\hline GSG & 20 & $1.49(0.08)$ & $1.45-1.53$ & $1.86(0.11)$ & $1.81-1.91$ & $<0.001$ \\
\hline LRG & 16 & $1.59(0.13)$ & $1.52-1.66$ & $2.07(0.12)$ & $2.00-2.13$ & $<0.001$ \\
\hline RG & 20 & $1.56(0.17)$ & $1.48-1.64$ & $1.84(0.18)$ & $1.76-1.93$ & $<0.001$ \\
\hline
\end{tabular}

${ }^{*}$ Comparasion between means of CFI objective and subjective of each breed.

Westerners, Japanese, and Chinese, and concluded that there was a marked difference in the femurs of the Indian population compared with that of the other ethnicities. Additionally, according to the channel flare index of Indians, they would benefit from the cementless fixation system as the best choice, a result that endorses the importance of determining the femoral CFI of dogs.

SEVIL-KILIMCI \& KARA (2017) compared femoral morphology of different breeds of dogs, German Shepherds and Kengal Dogs and concluded that some indexes analyzed in the metaphyseal corticomedullary region were significantly different from each other, which corroborated the hypothesis of this study by demonstrating different morphological patterns in each race studied.

However, the values obtained by these authors and by PALIERNE et al. (2006) differed from those obtained in this study, which observed lower CFI values in the $95 \%$ confidence interval. This fact can be explained by the metaphyseal region used to measure the CFI. In this study, the intracortical width at the height of the lesser trochanter was used, whereas PALIERNE et al. (2006) and SEVIL-KILIMCI \& KARA (2017) used the intracortical width at the

Table 2 - Interobserver comparison of mean and standard deviation (SD) of CFI Subjective (CFIsub) and CFI Objective (CFIob) for dogs of different breeds: Golden Retrievers (GRG), German Shepherds (GSG), Labrador Retrievers (LRG), and Rottweilers (RG).

\begin{tabular}{|c|c|c|c|c|}
\hline \multirow[t]{2}{*}{ Breed } & \multicolumn{3}{|c|}{ 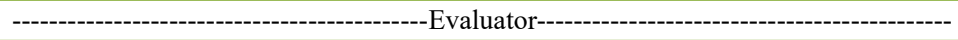 } & \multirow[t]{2}{*}{$\mathrm{P}$ value } \\
\hline & 2 & 1 & 3 & \\
\hline GRG & $2.01(0.32)^{\mathrm{a}}$ & $2.00(0.35)^{\mathrm{a}}$ & $2.27(0.43)^{\mathrm{b}}$ & 0.0134 \\
\hline GSG & $1.84(0.17)^{\mathrm{a}}$ & $1.65(0.17)^{b}$ & $2.10(0.30)^{\mathrm{c}}$ & $<0.0001$ \\
\hline LRG & $1.95(0.17)^{\mathrm{a}}$ & $1.89(0.18)^{\mathrm{a}}$ & $2.36(0.27)^{\mathrm{b}}$ & $<0.0001$ \\
\hline RG & $1.76(0.21)^{\mathrm{a}}$ & $1.67(0.20)^{\mathrm{a}}$ & $2.11(0.38)^{b}$ & $<0.0001$ \\
\hline Geral mean & $1.87(0.24)^{\mathrm{a}}$ & $1.78(0.26)^{\mathrm{b}}$ & $2.19(0.36)^{\mathrm{c}}$ & $<0.0001$ \\
\hline \multirow[t]{2}{*}{ Breed } & --------------------- & -Evaluator----. & ---------------------- & $P$ value \\
\hline & 2 & 1 & 3 & \\
\hline GRG & $1.61(0.21)^{\mathrm{a}}$ & $1.57(0.26)^{\mathrm{a}}$ & $1.87(0.37)^{b}$ & 0.0011 \\
\hline GSG & $1.41(0.11)^{\mathrm{a}}$ & $1.29(0.15)^{\mathrm{b}}$ & $1.77(0.22)^{\mathrm{c}}$ & $<0.0001$ \\
\hline LRG & $1.47(0.14)^{\mathrm{a}}$ & $1.44(0.18)^{\mathrm{a}}$ & $1.86(0.26)^{b}$ & $<0.0001$ \\
\hline RG & $1.50(0.19)^{\mathrm{a}}$ & $1.43(0.19)^{\mathrm{a}}$ & $1.74(0.26)^{b}$ & $<0.0001$ \\
\hline Geral mean & $1.49(0.18)^{\mathrm{a}}$ & $1.42(0.22)^{\mathrm{a}}$ & $1.80(0.28)^{\mathrm{b}}$ & $<0.0001$ \\
\hline
\end{tabular}

*Comparison in ANOVA among the three evaluators.

Different letters $(a, b, c)$ indicate statistical difference by Tukey test $(\mathrm{P} \leq 0.05)$. 
proximal end of the lesser trochanter, which matched an anatomically larger region. A recently published study by SEVIL-KILIMCI \& KARA (2020) concluded that the location of the measurement of the width of the spinal canal in proximal femurs may impact CFI values.

Although, German Shepherd presented the lowest CFI values, all races evaluated presented stovepipe-type femurs when considering the objective measurement of CFI. However, the values were different when comparing the measurements between CFIob and CFIsub. The data reported this research were in accordance with those reported by RASHMIR-RAVEN et al. (1992), GANZ et al. (2010), PUGLIESE (2014), and SEVIL-KILIMCI \& KARA (2017), which demonstrated that German Shepherds presented lower CFI values compared to other breeds and among the breeds studied by other authors have lower values compared to Golden Retrievers and Labrador Retrievers, configuring femurs with more pronounced morphology within the stovepipe classification.

Results were corroborated by PUGLIESE (2014), because the German Shepherds (1.57) had the lowest CFI values, followed by the Golden Retriever (1.78) and Labrador Retriever (1.84). The same was observed in this study, in which the German Shepherd's CFIob was 1.49, whereas the Golden Retriever was 1.68 and the Labrador Retriever was 1.59 , and German Shepherd's CFIsub value was 1.86, whereas the Golden retrievers were 2.09 and Labrador retrievers was 2.07.

LISKA and DOYLE (2015) evaluated the CFI of different races for their study and the average of the values obtained differed from that in this research. The average CFI reported by these authors for the Golden Retriever breed was 1.3, German Shepherd 1.3, Labrador 1.48, and Rottweiler 1.4, whereas in this study, we obtained CFIob values of $1.68,1.49$, 1.59 , and 1.56 for these breeds, respectively.

The measurements of the objective and subjective CFI had significantly different values, and the subjective measurements showed higher values compared to the objective measurement for each race, as demonstrated by SEVIL-KILIMCI \& KARA (2020). Therefore, further studies were conducted on these values to determine the standard reliable measurement location to obtain this evaluation parameter, which is extremely important for the preoperative planning of THA.

These methods differed with respect to the measurement of the femoral fraction regarding the mathematical formula used to calculate the CFI and were similar to that reported by ANDRADE et al. (2019), who obtained values that differed from those found by PALIERNE et al. (2006) because they used different anatomical references to calculate the CFI. When establishing the measurement of the medullary canal at the height of the midpoint of the femoral length, it was not always similar to the femoral isthmus, presenting a higher value compared to that obtained when performing the subjective measurement, that is, the region with the lowest canal width diaphyseal femoral medulla.

In the literature, few studies have assessed the intraobserver and interobserver variability in measuring CFI from radiographs in ventrodorsal projection using different anatomical references. Intraobserver variability was not reported in this study, which was in agreement with that demonstrated by CAYLOR et al. (2001), UNIS et al. (2010), and ANDRADE et al. (2019), where even using evaluators with different levels of experience, they did not present significant differences in this evaluation.

According to CAYLOR et al. (2001), who studied the measurements of the angle of the tibial plateau in dogs, the high degree of reproducibility in intraobserver measurements suggested that all evaluators could consistently and faithfully reproduce the measurements of the angle of inclination of the tibial plateau using radiography. In this context, UNIS et al. (2010) suggested that no difference was observed in the intra-observer variability of their study because of the ability of the evaluators to identify the reference points used to calculate the angle of the tibial plateau of dogs on radiographs, implying that the correct identification anatomical reference points in radiographic measurements may be more important than the quality of the image or even the surgical experience of the evaluators.

Interobserver variability was observed in the study, according to the ANOVA and Tukey test $(\mathrm{P} \leq 0.05)$, between the evaluator 3 with evaluators 1 and 2 in the Labrador Retriever, Golden Retriever, and Rottweiler breeds, and among all evaluators in the German Shepherd breed in both the objective CFI and subjective CFI. It was caused by the imprecision in the reference points for such an evaluation, as previously discussed.

The form of manual measurement influenced these results. ALVES etal. (2018) compared the methods of manual and digital evaluation of the tibial plateau and concluded that the manual method was inferior to the digital method because it is more difficult and resulted in a greater variation in values, which corroborated the data in this study when 
demonstrating lower reproducibility when performing manual measurements. Alternatively, SERWA et al. (2009) reported no statistical difference in their research when comparing the method of manual and digital evaluation in the preoperative planning of the tibial plateau leveling osteotomy.

In this context, WAKO et al. (2018) studied the intra- and interobserver variation of threedimensional preoperative planning in THA in humans, and similar to INOUE et al. (2015), concluded that there was excellent interobserver and intraobserver reliability in terms of component size and alignment in THA, but the deformity of the affected joint influenced the reliability of preoperative planning.

\section{CONCLUSION}

There was standardization in the CFI values of each breed; however, these values did not change the classification in which these animals fit in relation to the proximal femoral morphology when using the objective measurement, being all classified as stovepipe. Additionally, the discrepancy in values obtained when measuring the CFI and difference reported when comparing the values between the different evaluators could be attributed to the different anatomical references used to measure this parameter, which confirmed the need for standardization of measurement in dogs, such that, there is no inconsistency in the data in the literature because of the methodology used to measure this tool, which is important for preoperative planning of THA in dogs.

\section{ACKNOWLEDGEMENTS}

The authors want to thank the Conselho Nacional de Dsenvolvimento Científico e Tecnicológico (CNPq) for the Ph.D's scholarship (PRGS) awarded and financial support provided.

\section{ETHICS COMMITTEE APPROVAL}

This research was approved by the Comissão de Ética na Utilização de Animais (CEUA) of the Faculdade de Ciências Agrárias e Veterinárias (FCAV) of Universidade Estadual Paulista (UNESP), Jaboticabal, São Paulo State, under protocol no. 0830/19.

\section{DECLARATION OF CONFLICTS OF INTERESTS}

The authors declare no conflict of interest. The founding sponsors had no role in the design of the study; in the collection, analysis, or interpretation of data; in the writing of the manuscript, and in the decision to publish the results.

\section{AUTHOR'S CONTRIBUTION}

All authors contributed to the development of this research.

\section{REFERENCES}

ALVES, A.M. et al. Comparative study of manual and digital method in the calculation of the tibial plateau angle in dogs. Arquivo Brasileiro de Medicina Veterinária e Zootecnia, v.70, n.1, p.117121, 2018. Available from: <https://doi.org/10.1590/1678-41629213>. Accessed: Jan. 23, 2019. doi: 10.1590/1678-4162-9213.

ANDRADE, C. de et al. Accuracy in determining canal flare index using different radiographical positions for imaging canine femurs. Veterinary and Comparative Orthopaedics and Traumatology, v.32, n.3, p.234-240, 2019. Available from: <http://dx.doi. org/10.1055/s-0039-1683390>. Accessed: Aug. 15, 2019. doi: $10.1055 / \mathrm{s}-0039-1683390$

BAHARUDDIN, M. Y. et al. Morphological study of the newly designed cementless femoral stem. BioMed Research International, v. 2014, article ID 692328, p.1-11, 2014. Available from: <https://doi.org/10.1155/2014/692328>. Accessed: Nov. 23, 2018. doi: $10.1155 / 2014 / 692328$.

BERGH, M. S.; BUDSBERG, S. C. A systematic review of the literature describing the efficacy of surgical treatments for canine hip dysplasia (1948-2012). Veterinary Surgery, v.43, n.5, p.501-506, 2014. Available from: <http://dx.doi.org/10.1111/ j.1532-950x.2014.12208.x>. Accessed: Nov. 23, 2018. doi: 10.1111/j.1532-950X.2014.12208.x.

BOER, F. A. de; SARIALI, E. comparison of anatomic vs. straight femoral stem design in total hip replacement - femoral canal fill in vivo. Hip International, v.27, n.3, p.241-244, 2016. Available from: <https://doi.org/10.5301/hipint.5000439>. Accessed: nov 23, 2018. doi: 10.5301/hipint.5000439.

CAYLOR, K. B. et al. Intra- and interobserver measurement variability of tibial plateau slope from lateral radiographs in dogs. Journal of The American Animal Hospital Association, v.37, n.3, p.263-268, 2001. Available from: <https://doi. org/10.5326/15473317-37-3-263>. Accessed: Nov. 23, 2018. doi: $10.5326 / 15473317-37-3-263$.

CROOIJMANS, H. J. A. et al. A new digital preoperative planning method for total hip arthroplasties. Clinical Orthopaedics and Related Research, v.467, n.4, p.909-916, 2008. Available from: $<$ http://dx.doi.org/10.1007/s11999-008-0486-y>. Accessed: Nov. 23, 2018. doi: 10.1007/s11999-008-0486-y.

DEYOUNG, D. J.; SCHILLER, R. A. Radiographic criteria for evaluation of uncemented total hip replacement in dogs. Veterinary Surgery, v.21, n.2, p.88-98, 1992. Available from: $<$ https://doi. org/10.1111/j.1532-950X.1992.tb00021.x>. Accessed: Nov. 23, 2018. doi: 10.1111/j.1532-950x.1992.tb00021.x.

FLECHER, X. et al. Custom cementless stem improves hip function in young patients at 15-year followup. Clinical Orthopaedics and Related Research, v.468, n.3, p.747-755, 2010. Available from: $<$ https://doi.org/10.1007/s11999-009-1045-x>. Accessed: Nov. 23, 2018. doi: 10.1007/s11999-009-1045-x. 
GANZ, S. M. et al. Risk factors for femoral fracture after canine press-fit cementless total hip arthroplasty. Veterinary Surgery, v.39, n.6, p.688-695, 2010. Available from: <https:// doi.org/10.1111/j.1532-950X.2010.00694.x>. Accessed: Nov. 23, 2018. doi: 10.1111/j.1532-950X.2010.00694.x

HENDERSON, E. R. et al. Evaluation of variables influencing success and complication rates in canine total hip replacement: results from the British Veterinary Orthopaedic Association Canine Hip Registry (collation of data: 2010-2012). Veterinary Record, v.181, n.1, p.18, 2017. Available from: <http://dx.doi.org/10.1136/ vr.104036>. Accessed: Nov. 23, 2018. doi: 10.1136/vr.104036.

INOUE, D. et al. Value of computed tomography-based threedimensional surgical preoperative planning software in total hip arthroplasty with developmental dysplasia of the hip. Journal of Orthopaedic Science, v.20, n.2, p.340-346, 2015. Available from: $<$ https://doi.org/10.1007/s00776-014-0683-3>. Accessed: Nov. 23, 2018. doi: 10.1007/s00776-014-0683-3.

KIDD, S. W. et al. Complications of porous-coated pressfit cementless total hip replacement in dogs. Veterinary and Comparative Orthopaedics and Traumatology, v.29, n.5, p.402408, 2016. Available from: <http://dx.doi.org/10.3415/vcot-15-070116>. Accessed: Nov. 23, 2018. doi: 10.3415/VCOT-15-07-0116.

LISKA, W.D.; DOYLE, N.D. Use of an electron beam melting manufactured titanium collared cementless femoral stem to resist subsidence after canine total hip replacement. Veterinary Surgery, v.44, n.7, p.883-894, 2015. Available from: <http:// https://pubmed.ncbi.nlm.nih.gov/26138323>. Accessed: Nov. 23, 2018. doi: $10.1111 /$ vsu. 12353 .

PALIERNE, S. et al. Geometric analysis of the proximal femur in a diverse sample of dogs. Research in Veterinary Science, v.80, n.3, p.243-252, jun. 2006. Available from: <https://doi. org/10.1016/j.rvsc.2005.07.010>. Accessed: Nov. 23, 2018. doi: 10.1016/j.rvsc.2005.07.010.

PUGLIESE, L. C. Proximal femoral morphology and bone quality assessment in dogs. 2014. $132 \mathrm{f}$. Master thesis Comparative and Veterinary Medicine, The Ohio State University, Ohio, United States.

RASHMIR-RAVEN, A. M. et al. Subsidence of an uncemented canine femoral stem. Veterinary Surgery, v.21, n.5, p.327331, 1992. Available from: <http://dx.doi.org/10.1111/j.1532950x.1992.tb01705.x.>. Accessed: Nov. 23, 2018. doi: 10.1111/j.1532-950x.1992.tb01705.x.

RAWAL, B. et al. Anthropometric measurements to design bestfit femoral stem for the Indian population. Indian Journal of Orthopaedics, v.46, n.1, p.46-53, 2012. Available from: <https:// www.ncbi.nlm.nih.gov/pmc/articles/PMC3270605>. Accessed: Nov. 23, 2018. doi: 10.4103/0019-5413.91634.
ROBERTS, T.; MCGREEVY, P. D. Selection for breed-specific long-bodied phenotypes is associated with increased expression of canine hip dysplasia. The Veterinary Journal, v.183, n.3, p.266-272, 2010. Available from: <https://doi.org/10.1016/j. tvj1.2009.11.005>. Accessed: Nov. 23, 2018. doi: 10.1016/j. tvj1.2009.11.005.

SARIALI, E. et al. Accuracy of the preoperative planning for cementless total hip arthroplasty. A randomised comparison between three-dimensional computerised planning and conventional templating. Orthopaedics \& Traumatology: Surgery \& Research, v.98, n.2, p.151-158, 2012. Available from: $<$ https://doi.org/10.1016/j.otsr.2011.09.023>. Accessed: Nov. 23, 2018. doi: 10.1016/j.otsr.2011.09.023.

SCHMIDUTZ, F. et al. Influence of different sizes of composite femora on the biomechanical behavior of cementless hip prosthesis. Clinical Biomechanics, v.41, p.60-65, 2017. Available from: $<$ https://doi.org/10.1016/j.clinbiomech.2016.12.003>. Accessed: Nov. 23, 2018. doi: 10.1016/j.clinbiomech.2016.12.003.

SEVIL-KILIMCI, F.; KARA, M. E. The geometry of the proximal femoral medullary canal in german shepherd and kangal dogs. Journal of the Faculty of Veterinary Medicine Istanbul University, v.43, n.1, p.52-60, 2017. Available from: <https:// actavet.org/en/the-geometry-of-the-proximal-femoral-medullarycanal-in-german-shepherd-and-kangal-dogs-1679>. $\quad$ Accessed: Nov. 23, 2018. doi: 10.16988/iuvfd.270288.

SEVIL-KILIMCI, F., KARA, M.E. Canal flare index in the canine femur is influenced by the measurement method. Veterinary and Comparative Orthopaedics and Traumatology, v.33, n.3, p.198204, 2020. Available from: <https://www.thieme-connect.com/ products/ejournals/abstract/10.1055/s-0040-1701501>. Accessed: Sep. 9, 2020. doi: 10.1055/s-0040-1701501.

SERWA, D. et al. Comparison of conventional and digital measurements of tibial plateau angle in dogs. Journal of The American Veterinary Medical Association, v.234, n.5, p.622-624, 2009. Available from: <https://doi.org/10.2460/javma.234.5.622>. Accessed: Nov. 23, 2018. doi: 10.2460/javma.234.5.622.

UNIS, M. D. et al. Evaluation of intra- and interobserver variability and repeatability of tibial plateau angle measurements with digital radiography using a novel digital radiographic program. Veterinary Surgery, v.39, n.2, p.187-194, 2010. Available from: $<$ https://pubmed.ncbi.nlm.nih.gov/20210966>. Accessed: Nov. 23, 2018. doi: 10.1111/j.1532-950X.2009.00641.x.

WAKO, Y. et al. Interobserver and intraobserver reliability of three-dimensional preoperative planning software in total hip arthroplasty. The Journal of Arthroplasty, v.33, n.2, p.601-607, 2018. Available from: <https://doi.org/10.1016/j. arth.2017.08.031>. Accessed: Nov. 23, 2018. doi: 10.1016/j. arth.2017.08.031. 